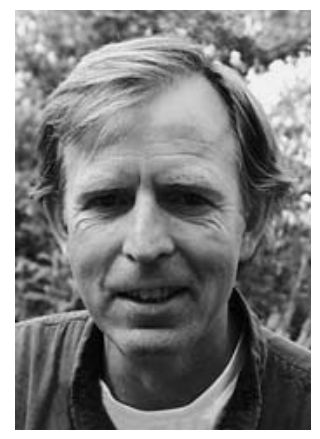

\title{
From Germany to India and Back
}

Starting this year 2010 LINKS is printed and published in Delhi. The Indian edition that for many years as a work of love was published by Research and Charities in Mumbai is now also produced by Thieme Publishers Delhi. I wish to thank the people from Thieme Stuttgart for their dedication to LINKS in the past five years, Rajan Sankaran and his colleagues for their work of love over two decades, and all for cooperating so wonderfully in the transition. I trust that by having both editions published in Delhi LINKS will flourish as never before.

Every transition has its 'initial aggravation' and this one was expressed through a delayed delivery of issue $1 / 2010$, as the authorisation process for publishing an international journal in India took more time than anticipated. I hope this didn't let you suffer too much. By now we are beyond the primary action of this change and may expect to enjoy the benefits due to the secondary healing response.

In the history of homeopathy the movement to the east, especially from Germany to India, is a significant one. There is no country in the world where so many homeopaths are being trained and so many patients treated with homeopathy as in India, and nowhere so many homeopathic research institutes, hospitals and clinics further spread Hahnemann's gift to mankind. As we can see from the impressive amount of Indian authors, teachers and (e)journals a meaningful stream of homeopathic knowledge and experience flows from India back to Germany and the rest of the world.

It is being said that the success of homeopathy in India is related to the fact that homeopathic philosophy is so similar to ancient Indian philosophy. Besides that homeopathy as a complete system of healing covering almost all indications can also reach the poor masses in the world because it is cheap, safe and effective.

As today's reality shows homeopathy could easily be integrated within Indian society. How far can a reciprocal relationship be recognised and can (parts of) Indian philosophy be integrated into homeopathic philosophy and practice?

My estimation is that of the current generation of homeopaths worldwide many are open to a newly evolving spiritual paradigm that transcends the apparent contradictions between east and west, and combines the best from both traditions and walks of life. In that sense homeopaths in general are open to the spiritual tradition of India, and we also find that more and more threads derived from eastern philosophy are woven into the art and science of homeopathy.

In this issue of LINKS you find several articles as examples of the above. They range from Hahnemannian provings of typically Indian 'substances' to global intention projects using homeopathic substances to induce change in the clearly deranged collective Dynamis, and from provings of material substances like Himalayan Crystal Salt to mystical substances like Vibhuti, from a thorough discussion of the 'salt' of homeopathic literature - the Organon - to relating Posology to the energy system of chakras and to how sound and colour remedies can be used based on the same.

This is an issue that, I realise, combines many different topics of which several still need to stand the test of time by showing consistent and reproducible results in the everyday practice of homeopaths. A sound and practical advice that does justice to the interest of our patients is to test new ideas or approaches in those cases where your current understanding and practice has reached its limits. That is the responsible way in which a medical science evolves, and that is how with full knowledge and acknowledgement of the foundation of homeopathy through trial and error our art and science further evolves.

Harry van der Zee, Editor 